\title{
OPPOSITIONAL STANCE AND FOOTING SHIFTS IN RESPONSES TO CUSTOMER COMPLAINTS ON TRIPADVISOR
}

Keywords: facework, footing, relational work, stance, TripAdvisor

\begin{abstract}
This paper reports on the results of a sociopragmatic study of restaurant-owners' public responses to negative customer reviews posted on TripAdvisor. Responses to customer complaints are typically apologetic, taking a deferential stance towards the customer. This study focuses on responses which shift away from this default position and take an explicitly oppositional stance. Drawing on Goffman's concept of footing and informed by sociopragmatic theories of facework and relational work, I explore the discursive mechanisms and linguistic resources by which restaurant-owners manipulate the footings which underlie their responses to complaints - with a particular focus on radical reframings of the participants' status and roles (the customer may be publicly denigrated or mocked). Such practices reflect the dynamic, fluid nature of a genre that may at first sight appear to be highly conventional in nature.
\end{abstract}

\section{Introduction}

This paper presents the results of a sociopragmatic study focusing on a genre that has emerged during the past decade: businesses' responses to customer complaints (negative reviews) on the TripAdvisor website. TripAdvisor is one of a growing number of websites that provide a forum for consumers to review services and products - in this case hotels, restaurants, cafés, bars, and various tourist attractions. As part of the TripAdvisor format, the owners or managers of these businesses have the right to respond to customers' reviews - to thank the customer, explain 
why any problems occurred, apologize, promise future improvements, and so on. Like the customers' reviews, these responses are in the public domain; they can be viewed by any visitor to the website. Though a number of studies in recent years have explored the discourse of customer complaints (an overview is given in Orthaber, Márquez-Reiter 2011: 3861-3862), including a study of complaints on TripAdvisor (Vásquez 2011), businesses' responses to complaints have received less attention, and studies of complaint responses in the public domain (e.g. Page 2014; Ho 2017) are still rare. The present study therefore aims to contribute to a deeper understanding of the sociopragmatic aspects of this still-emerging genre.

Businesses' responses to negative reviews on TripAdvisor tend to be broadly apologetic (cf. Page 2014), characterized by an acceptance of the customer's criticism and a rather deferential tenor. However, in some cases there is a shift away from this default position, and the respondent instead decides to take an explicitly oppositional stance - denying the customer's claims, criticizing the review for its lack of accuracy or fairness, and sometimes even mounting personal attacks on the reviewer. Such oppositional responses occur less frequently than their apologetic counterparts, but they are of considerable interest from a sociopragmatic perspective, and it is these responses that I explore in this study. I seek to provide an insight into this type of discursive practice by carrying out a qualitative analysis of a corpus of oppositional responses posted by restaurants, cafés and bars in three cities (Dublin, Manchester, Melbourne). Anchored in an ethnomethodological approach, my analysis draws on Goffman's (1981) concept of footing. I map how respondents' footing departs from the "default" position (i.e. the apologetic, deferential tenor found in most responses), and I explore the discursive mechanisms and linguistic resources through which such shifts in footing are accomplished.

\section{The genre}

This section briefly outlines the social and communicative context in which the genre of public online complaint responses is situated, focusing on three key factors. Here I describe the prototypical situation found in the majority of examples of the genre, characterized by an overwhelmingly non-oppositional stance. This can be viewed as the default setting - the norm from which the oppositional responses (the main subject of this study) deviate.

The first factor of fundamental importance is the relationship between the genre's two primary participants: the speaker $(\mathrm{S}$ - the respondent, i.e. the business owner or manager) and the hearer ( $\mathrm{H}$ - the reviewer or complainant, i.e. the customer). The social situation in which public complaint responses are embedded is characterized by a clear imbalance of status between $\mathrm{S}$ and $\mathrm{H}$, an imbalance which is rooted in the transactional roles played by both participants. The act of paying for a service establishes a relationship based on mutual rights and obligations; within the bounds of this commercial relationship, the customer essentially buys power over the service provider. This creates an expectation that the customer will be treated 
with a certain degree of deference (though the degree of deference that is felt to be appropriate will differ between cultures, and it will also depend on factors such as the type and price-bracket of the establishment).

The second important factor is the communicative purpose of the genre, which can be viewed in terms of two key sociopragmatic concepts - facework and relational work. With regard to Goffman's (1955/1967) concept of facework, the negative review represents a face-threatening act (FTA) as it publicly threatens the business's "institutional face" (Orthaber, Márquez-Reiter 2011: 3863). The response to the review thus offers an opportunity for the representative of the business to restore this damaged face by offering sympathy, apologies, explanations, remedy or compensation, thus demonstrating that they are aware of and responsive to their customers' needs; Kampf (using the term "persona” synonymously with Goffman's concept of face) observes that a public apology enables the apologizer to demonstratively "project a moral persona and reconstruct public trust" (Kampf 2009: 2259). With regard to the concept of relational work (Locher, Watts 2005, 2008, etc.), responses to negative reviews offer an opportunity to repair the damaged relationship between the business and the customer; this is why most responses centre around some form of apology and also include other placatory acts (such as expressions of gratitude or appreciation of the review).

The third key factor shaping discursive practices in this genre is its participatory framework. Public complaint responses expand the traditional dyad of primary participants (complainant-respondent) to include readers of the website, who essentially function as an audience observing the complaint-response exchange; I term these readers "third parties". Drawing on Goffman's (1981) division of ratified hearers into addressed and unaddressed recipients, Dynel (discussing the discourse of online interaction) defines a third party as "a ratified listener to whom an utterance is not addressed but who is fully entitled to listen to it and make inferences, according to the speaker's communicative intention" (Dynel 2014: 40). The existence of this "audience" has important implications for the discursive practices found in the genre: respondents are attempting not only to repair their relationship with the original complainant, but also to create a good impression on third parties. Most of these third parties are likely to be potential customers using TripAdvisor to help them choose a restaurant, café, bar, etc., so a well-handled response ultimately offers the possibility of significant commercial gain.

\section{Footing and shifts in footing}

The concept of footing was developed by Goffman (1981) as an extension of his (1974) concept of frames and framing in interactive social encounters. Footing is related to Goffman's notion of "alignment" (though he also uses other terms, e.g. "stance" or "position", more or less synonymously). Goffman (1981:128) defines footing as "the alignment we take up to ourselves and the others present as expressed 
in the way we manage the production or reception of an utterance. A change in our footing is another way of talking about a change in our frame for events [...] participants over the course of their speaking constantly change their footing, these changes being a persistent feature of natural talk".

There are three key elements of the concept of footing which are of particular importance to this study. Firstly, what is central here is the interpersonal (relational, social) dimension of communication. Footing is essentially interpersonal stance; it concerns the way in which participants in an interaction are positioned in relation to each other, and it is essentially the interpersonal foundation on which the discourse is built. Ribeiro and Hoyle (2009: 79) characterize footing as "the stance that speakers and hearers take toward each other and toward the content of their talk" [emphasis added]. Due to the relational imbalance (status gap) between $\mathrm{S}$ and $\mathrm{H}$, public online responses to negative reviews tend to stand on a deferential footing, which is indexed by a range of verbal acts (acceptance of criticism, apology for the transgression, offer of repair, etc.), typically overlaid with various politeness formulas. This is the "default" footing; a previous study of the genre (Hopkinson forthcoming) found that around 70 percent of analyzed responses included speech acts of apology.

Secondly, as Goffman notes in the definition given above, footing is not static; like other Goffmanian concepts (such as face or identity performance) it is fluid and dynamic, constantly shifting as it is (re)negotiated between participants in interaction. As Ribeiro and Hoyle note (2009: 79), "[a] frame [...] is constructed through participants' signalling their own and recognizing and ratifying one another's footing - which may and usually does change from moment to moment". In the genre investigated here, we can sometimes observe a radical departure from the default footing, which may be abandoned entirely. For example, the respondent (S) may decide to direct criticism or accusations at the complainant $(\mathrm{H})$; such acts index a fundamental shift in footing, disrupting the default role templates which underpin typical examples of the genre and leading to a reframing of the discourse.

Thirdly, Goffman's concept of footing is intimately bound up with language; footing is "expressed in the way we manage the production or reception of an utterance" (Goffman 1981: 128), and Goffman also notes that "linguistics provides us with the cues and markers through which such footings become manifest" (Goffman 1981: 157). Participants in interaction use a range of discursive practices and linguistic resources to signal their footing and ratify the footings of others - and it is these practices and resources that the present study explores. The analysis operates mainly on the level of discourse semantics, particularly speech acts and their illocutionary force, though I also discuss a number of key lexicogrammatical resources used on the locutionary level. Analyzing a corpus consisting of responses which express some degree of oppositional stance, I present a typology of the main footing shifts and I seek to identify the most prevalent discursive mechanisms and linguistic resources through which these shifts are manifested. 


\section{Material and methods}

The corpus analyzed for this study consists of 294 responses to negative reviews of restaurants, cafés and bars posted on TripAdvisor. The corpus was compiled between March 2016 and January 2017 using the following process. TripAdvisor uses a rating system whereby reviewers (customers) grade establishments on a scale from a minimum 1 point ("terrible") to a maximum 5 points ("excellent"). For the purposes of this study, negative reviews were defined as those rating the establishment as 1 or 2 points ("terrible" or "poor", respectively). If the owner/manager of the establishment posted a response, the response was assessed to determine whether it expressed some form of oppositional stance - disagreeing with the complainant's evaluation or version of events, expressing negative evaluations of the review or the complainant, and so on. Responses expressing oppositional stance were included in the corpus. The responses were collected from randomly selected establishments located in three cities: Dublin (Ireland), Manchester (United Kingdom) and Melbourne (Australia). The resulting corpus consists of 294 responses from 127 separate establishments, and it contains a total 62000 words (averaging 211 words per response). The responsess cover a period from May 2012 to January 2017.

A manual qualitative analysis of the corpus was then carried out in order to identify the main types of footing shifts than can be identified and the most prevalent discursive mechanisms and linguistic resources through which these shifts are manifested. The analysis thus proceeds from function to form. Quantitative analysis is beyond the scope of this study; this is partly due to the relatively small size of the corpus (a small corpus is necessary to enable an in-depth exploration of complex discursive practices) and partly due to the fact that most of the mechanisms and resources examined in the study resist simple classification into clear-cut categories. All examples given below have been anonymized where necessary in order to conceal the identity of both complainants and respondents.

\section{Results and discussion}

In this section I present and discuss the most prevalent discursive mechanisms and linguistic resources through which footing shifts are manifested in the analyzed corpus. Some of the responses remain essentially anchored within the default footing. Though they do include some elements of opposition, this stance is mitigated - either structurally (by juxtaposing oppositional acts with placatory acts such as apologizing to $\mathrm{H}$ or expressing appreciation for the review), or via various lexicogrammatical means of downgrading the illocutionary force of oppositional speech acts. Such responses thus exhibit a kind of "gravitational pull" back towards the default deferential footing, and they remain within the default frame. Due to space constraints, these responses are not discussed here.

Other responses display a more radical and permanent departure from the default footing, bringing about a full-scale interpersonal repositioning of the participants. 
Goffman's (1981: 128) concept of framing is of particular relevance here, as "[a] change in our footing is another way of talking about a change in our frame for events"; by abandoning the default footing, these responses bring a fundamental reframing of the discourse.

Below I discuss these footing shifts on two levels. On the more general level, I describe the main ways in which the default relational imbalance (status gap) between $\mathrm{S}$ and $\mathrm{H}$ is subverted (section 5.1). This default imbalance of status is also manifested on a more specific level in the roles that are recurrently enacted by both primary participants within complaint-response exchanges (e.g. reviewer-reviewee, challenger-respondent, victim-perpetrator); in section 5.2 I describe how the roles of the participants within these role templates are often reversed.

\subsection{Departures from participants' default relational status}

When there is a departure from the default footing, the relational status of $\mathrm{S}$ and $\mathrm{H}$ is often inverted, and $\mathrm{S}$ signals not deference towards $\mathrm{H}$, but rather the opposite relational stance: contempt for H. This signalling - i.e. Goffman's (1981: 157) “cues and markers through which [...] footings become manifest"- is performed via a broad range of discursive mechanisms and linguistic resources. Below I discuss the four main types observed in the corpus.

(a) The inversion of relational status may be signalled by choices of encoding i.e. the lexicogrammatical means by which the participants are encoded in the discourse. In most examples of the genre, $\mathrm{H}$ is encoded via second-person forms (and by speech acts which address $\mathrm{H}$ directly). However, in some cases $\mathrm{S}$ signals a footing shift (inversion of relational status) by using third-person encoding - effectively the respondent "turns away" from the complainant and addresses third parties (the audience) instead (examples of this type of encoding were found in 30 responses in the corpus). In the following example, $S$ responds to a customer's negative review by offering an alternative account of the incident, in an attempt to set the record straight:

(1) On this occasion, as members of the table were unable to identify what food had already been served to them, were slurring and swearing at staff, we made the decision to stop serving alcohol to the table. Further to this, when members of the table took to throwing food at the team members and dipping their fingers in the adjacent table's dessert, we made the difficult decision to remove the table from the building in order to protect the night for other guests.

Such footing shifts serve a clear strategic purpose in terms of the relational work done by S; they can be interpreted as attempts to drive a wedge between the complainant and the third-party readers and to persuade these third parties not to feel sympathy with the complainant, but instead to side with the respondent (the victim of the complainant's unfair/dishonest review or - as in this case - unacceptable behaviour). This "turning away" from the complainant can be seen as analogous to 
turning one's back on a person during a face-to-face conversation, which Culpeper (2011: 136) identifies as a type of conventionalized non-verbal impoliteness behaviour; the face-threatening potential of its verbal equivalent is clear.

(b) Other signals of this inversion of relational status include various types of ironic (sarcastic) verbal behaviour which have the effect of ridiculing $\mathrm{H}$ (examples of such behaviour were found in 36 responses in the corpus). The offensive potential of irony was recognized by Leech when he proposed the Irony Principle as a kind of negative counterpart to his Politeness Principle, as irony "allows the hearer to arrive at the offensive point of your remark indirectly, by way of implicature" (Leech 1983: 82). Likewise, Wilson (2013: 46) notes that "[t]he point of an ironical utterance is to express the speaker's own dissociative (e.g. mocking, scornful or contemptuous) attitude to a thought similar in content to the one expressed in her utterance [...]". When irony is used, there is a mismatch between the meaning that is encoded in the utterance, and the meaning that is derived from the pragmatic context. There is no explicit "illocutionary force indicating device" (Searle, Vanderveken 1985; BlumKulka, House, Kasper 1989); instead hearers interpret such utterances by making a contextual judgement based on their knowledge or expectation of the speaker's intentions. The following example is a response to a complaint that the restaurant serves only burgers:

(2) Thanks for your review. As you walk up to the building, there is a huge neon sign, a burger with wings, and as you enter there are two signs at the entrance which categorically state that we serve "burgers and booze" - sorry if these eluded you in your haste to get out of the rain. There are also many, many other pointers on your way around the building that might suggest that we are, indeed, a burger restaurant.

Though masquerading as a patient explanation, such a text is likely to be interpreted as ridiculing $\mathrm{H}$. The discourse thus indexes a lack of respect for $\mathrm{H}$, and the default footing of deference is replaced by a stance based on contempt.

Other types of ironic (sarcastic) verbal behaviour with the same relational effects include those that can be grouped under the heading of mock politeness - defined by Culpeper as "the use of politeness strategies that are obviously insincere, and thus remain surface realizations" (Culpeper 1996: 356). Whereas genuine politeness strategies attempt to enhance H's face, mock politeness attacks and denigrates H's face. Mock politeness in the corpus involves the parodic use of various speech acts which are prototypically deferential. S may thus use mock thanking (the insincerity of the underlined speech act is obvious from the wider context of the response, which ridicules $\mathrm{H})$ :

(3) thank you for taking the time to leave your valued opinion, ${ }^{1}$ it seems 2012 was your best year for enjoying life and since then it has been getting harder to get satisfaction - this is from your review ratings of course.

1 Here and in the following examples the emphasis is mine. 
We can also observe examples of mock apology. Apologies typically have a bipartite structure, consisting of an expression of stance (remorse) combined with a brief account of the offence. In the following example (a response to a complaint that some other guests in the bar were noisy) the insincerity of the apology is obvious from the account of the offence, when H's objection to other people having fun is clearly ridiculed:

(4) we can only apologise profusely to you for any inconvenience this may have caused you or your colleagues with these people out enjoying themselves and having fun

Other forms of mock politeness include mock advice with the purpose of ridiculing $\mathrm{H}$ (as in this response to a complaint about the high price of a restaurant meal):

(5) a suggestion the next time you are in Temple Bar there is a very good McDonalds close to us and they offer value food that is probably more compatible with your requirements.

and mock expressions of respect for $\mathrm{H}$ (here including an emoticon to help signal S's insincerity):

(6) who are we to argue with your venerable knowledge and expert opinion :)

(c) The third main type of resource which signals an inversion of relational status is the use of certain speech acts belonging to Searle's category of directives (Searle 1975) - particularly acts that are functionally close to commands, typically realized via imperative forms (examples of such speech acts were found in 28 responses in the corpus). Speech acts of this type are typically associated with an imbalance in status between the issuer of the command and its addressee; $S$ is demanding that $\mathrm{H}$ obey the command. As part of the inversion of participants' relational status in responses such as these, the service provider actually tells the customer what to do:

(7) OMG, we have not had tuna steak in our menu for at least the past 3 months [...] What else can I say look at our menu before you write such a long review.

(d) The final type of resource which (in a very obvious manner) indexes this shift of footing and inversion of relational status is performative speech acts of dismissal and exclusion, i.e. members of Searle's (1975) category of "declarations" (examples of such speech acts were found in 20 responses in the corpus). In terms of relational work, such responses represent attempts to drive a wedge between the complainant and third-party readers, constructing an in-group (the business plus "normal" members of the public) from which $\mathrm{H}$ is demonstratively excluded by means of the performative speech act. The following example (a response to the complainant's threat to take their business elsewhere in future) clearly contrasts the complainant with "normal" members of the public: 
(8) we will let the public assess how we rate with the vast majority of our TripAdvisor reviews. And yes, it's probably best if you stick to your promise to bring your business elsewhere...

while the following example performatively excludes the complainant from the ingroup on the basis of their unacceptable behaviour:

(9) You were barred for being rude, aggressive \& demanding to our staff. You made all our staff feel uncomfortable in their work place. You threatened our security \& manager with bad online reviews and you followed through on this. TripAdvisor will not take this down but advise responding with our side of the story. This is our response... Do everyone a favour, stay in your own bar. You're not welcome here in [name of bar].

\subsection{Departures from default role templates}

Having discussed footing shifts on the most general level (the inversion of the default relational status of $\mathrm{S}$ and $\mathrm{H}$ ), I now move on to explore the manifestations of footing shifts on a more specific level - that of the roles enacted by the two primary participants within the complaint-response exchange. I focus on the three most prevalent role templates within which the participants operate: reviewer-reviewee, challenger-respondent, and victim-perpetrator. These role templates are closely related, and they are often woven together within a single exchange. The individual roles also reflect the default gap in status that separates $\mathrm{S}$ and $\mathrm{H}$, as they are associated with certain expectations regarding the participants' rights and obligations. When there is a departure from the default footing, the roles of the two participants are typically reversed.

\section{(a) Role template reviewer-reviewee}

In the default footing, the customer $(\mathrm{H})$ is the reviewer (the critic) and the respondent (S) is the reviewee (the target of the criticism). $\mathrm{H}$ is licensed to criticize, while $\mathrm{S}$ is expected to take the criticism seriously and engage with its substance. However, when there is a departure from this default footing, the roles are reversed; $\mathrm{S}$ takes on the role of the reviewer, subjecting H's review to criticism. This type of footing shift is clearly signalled by the respondent's explicit negative evaluation of the review:

(10) your review lacks the detail of an honest dining assessment. [...] This is a peculiar review which tells us nothing about what we did wrong, but seems to be a deceptive commentary with no information, very strange.

Occasionally the face threat to $\mathrm{H}$ caused by this type of role reversal is intensified (aggravated) by a mechanism which elsewhere I have termed "echoic response" (Hopkinson 2012: 138). This is a device that is commonly used in antagonistic discourse to attack an opponent's face; it involves incorporating the opponent's previous words into one's own utterance and then "throwing them back" at the opponent, their 
original meaning twisted by their insertion into a new context. The following example is a response to a review which concludes with the words I wouldn't recommend this place to anyone ever!!!!! After a detailed refutation of the claims made in the review, the respondent recontextualizes the reviewer's original words as follows:

(11) By the way we would never recommend you either as a customer to any other poor restaurant EVER!!!!

Another manifestation of this type of role reversal is S's use of expressive speech acts conveying affective stance - most typically expressions of anger. In the default frame of customer complaint discourse, the customer is licensed to express a certain degree of anger or frustration, while the service provider is expected to "soak up" this anger and not reciprocate. However, if the reviewer-reviewee roles are reversed, the service provider gains the licence to express anger at the customer:

(12) I must admit to being extremely angry on this occasion as I feel your review is in no way measured

(b) Role template challenger-respondent

In the default footing, the customer's review can be seen as a challenge that places the business under a degree of obligation to respond. (This sense of obligation is reinforced by peer pressure dynamics; if competing businesses are regularly replying to their customers' reviews on TripAdvisor, this represents a powerful motivation for a business to reply its own customers' reviews.) When there is a departure from the default footing, the roles are reversed so that the respondent (S) becomes the challenger, using directive speech acts to demand a response from $\mathrm{H}$ :

(13) Please can you particularise your allegations that [restaurant name] is "filthy" and "uncomfortable" and explain why you have posted a review 6 months after your visit

In fact, TripAdvisor does not enable chains of correspondence to develop between reviewers and the owners/managers of businesses; the respondent has the last word. Such speech acts are thus purely rhetorical challenges, performed demonstratively for the purpose of persuading third-party readers by discrediting the complainant's claims.

\section{(c) Role template victim-perpetrator}

In the default footing, the complainant is the victim of (alleged) poor service, while the respondent is the perpetrator; this enables the complainant to claim the moral high ground over the respondent, creating an imbalance in what could be thought of as "moral status". However, when there is a departure from this default footing, the respondent claims victim status, while the original complainant is cast as the perpetrator, having posted a review which is unreasonable, dishonest or malicious. As Haugh (2015) and Tayebi (2016) have noted, the discursive practice of "taking offence" can represent a powerful form of social action, enabling the offended party to claim the moral high ground over their opponent. In such cases, respondents 
typically use speech acts of accusation, expressing negative evaluations of the review as unfair, wrong, and damaging, while contrastingly positioning themselves as exemplars of positive values such as hard work and honesty:

(14a) To accuse [restaurant] of giving you 'food poisoning' without evidence is wrong and damaging to the great reputation of the restaurant.

(14b) Never has a review [...] been so unfair to my staff who are just doing their job at the busiest time of the year under extreme pressure.

(14c) You have no right to slag off hard working people who are trying really hard 7 days a week to run an honest business.

As in several of the other examples discussed previously, the purpose of this practice is to drive a wedge between the complainant and third-party readers, persuading third parties to feel sympathy not with the complainant, but with the respondent instead.

\section{Conclusion}

In this paper I have set out to demonstrate that even in a genre that may at first sight appear to be highly conventional, footings and participant roles are in fact fluid and dynamic rather than fixed and stable. Proceeding from function to form, this study presents a typology of the main footing shifts observed in the corpus, identifying the most prevalent discursive mechanisms and linguistic resources which signal these shifts (with a particular focus on speech acts).

In some oppositional responses there is not a genuine shift away from the default footing; opposition is mitigated, and there is a gravitational pull back to the deferential norm of the genre. In other cases there is a radical departure from and abandonment of the default footing, typically involving an inversion of the participants' mutual relational status (S expresses contempt rather than deference) and a reversal of default roles. This represents a reframing of the discourse.

In addition to the two primary participants, the presence of third parties (TripAdvisor readers, i.e. potential customers) also influences the discursive practices used in the responses. Respondents attempt to persuade these third parties by discrediting the complainant, and they also engage in relational work - attempting to drive a wedge between the third parties and the reviewer. In other words, although such oppositional responses are considerably less frequent than their default deferential/apologetic counterparts, they are not necessarily mere aberrations - they can serve a distinct strategic purpose as part of the respondent's communication and marketing practices.

This article is an output of the University of Ostrava's internal grant project SGS10/ FF/2017 (Communication across cultures: Local and translocal features of genres online and offline). 


\section{Sources}

Dublin subcorpus (retrieved December 2016-January 2017)

https://www.tripadvisor.co.uk/Restaurants-g186604-County_Dublin.html

Manchester subcorpus (retrieved March 2016-August 2016)

https://www.tripadvisor.co.uk/Restaurants-g187069-Manchester_Greater_Manchester_

England.html

Melbourne subcorpus (retrieved July 2016-September 2016)

https://www.tripadvisor.co.uk/Restaurants-g255100-Melbourne_Victoria.html

\section{References}

Blum-Kulka S., House J., Kasper G. (eds.). 1989. Cross cultural pragmatics: Requests and apologies. Norwood (NJ).

Culpeper J. 1996. Towards an anatomy of impoliteness. - Journal of Pragmatics 25: 349-367.

Culpeper J. 2011. Impoliteness: Using language to cause offence. Cambridge (UK).

Dynel M. 2014. Participation framework underlying YouTube interaction. - Journal of Pragmatics 73: 37-52.

Goffman E. 1967. On face-work: An analysis of ritual elements in social interaction. - Goffman E. Interaction ritual: Essays in face-to-face behavior. Chicago: 5-45. [Originally published 1955. Psychiatry 18: 213-231].

Goffman E. 1974. Frame analysis: An essay on the organization of experience. Cambridge (MA).

Goffman E. 1981. Forms of talk. Philadelphia.

Haugh M. 2015. Impoliteness and taking offence in initial interactions. - Journal of Pragmatics 86: 36-42.

Ho V. 2017. Giving offense and making amends: How hotel management attempts to manage rapport with dissatisfied customers. - Journal of Pragmatics 109: 1-11.

Hopkinson C. 2012. Antagonistic facework in online discussion fora. - Hopkinson C., Tomášková R., Zapletalová G. (eds.). The interpersonal language function across genres and discourse domains. Ostrava: 113-152.

Hopkinson C. [forthcoming]. Saving face online: Institutional responses to negative customer reviews on TripAdvisor. - Lu W., Pelclová J. (eds.). Persuasion in public discourse. Amsterdam, Philadelphia.

Kampf Z. 2009. Public (non-)apologies: The discourse of minimizing responsibility. - Journal of Pragmatics 41: 2257-2270.

Leech G. 1983. Principles of pragmatics. London.

Locher M.A., Watts R.J. 2005. Politeness theory and relational work. - Journal of Politeness Research 1.1: 9-33.

Locher M.A., Watts R.J. 2008. Relational work and impoliteness: Negotiating norms of linguistic behaviour. - Bousfield D., Locher M.A. (eds.). Impoliteness in language: Studies on its interplay with power in theory and practice. Berlin: 77-99.

Orthaber S., Márquez-Reiter R. 2011. 'Talk to the hand.' Complaints to a public transport company. - Journal of Pragmatics 43: 3860-3876.

Page R. 2014. Saying 'sorry': Corporate apologies posted on Twitter. - Journal of Pragmatics 62: 30-45.

Ribeiro B.T., Hoyle S.M. 2009. Frame analysis. - Brisard F., Östman J.-O., Verschueren J. (eds.). Grammar, meaning and pragmatics. Amsterdam, Philadelphia: 74-90. 
Searle J.R. 1975. A taxonomy of illocutionary acts. - Günderson K. (ed.). Language, mind, and knowledge. Minneapolis (MN): 344-369.

Searle J.R., Vanderveken D. 1985. Foundations of illocutionary logic. Cambridge (UK).

Tayebi T. 2016. Why do people take offence? Exploring the underlying expectations. - Journal of Pragmatics 101: 1-17.

Vásquez C. 2011. Complaints online: The case of TripAdvisor. - Journal of Pragmatics 43: $1707-1717$.

Wilson D. 2013. Irony comprehension: A developmental perspective. - Journal of Pragmatics 59: 40-56. 
